\title{
WHO/UNEP global surveys of PCDDs, PCDFs, PCBs and DDTs in human milk and benefit-risk evaluation of breastfeeding
}

\author{
Martin van den Berg1 ${ }^{1} \cdot K^{-}$arin Kypke ${ }^{2} \cdot$ Alexander Kotz $^{2} \cdot$ Angelika Tritscher $^{3}$ • \\ Seoung Yong Lee ${ }^{3} \cdot$ Katarina Magulova $^{4} \cdot$ Heidelore Fiedler $^{5} \cdot$ Rainer Malisch $^{2}$
}

Received: 9 June 2016 / Accepted: 7 July 2016 / Published online: 20 July 2016

(C) The Author(s) 2016. This article is published with open access at Springerlink.com

\begin{abstract}
Since 1987, the World Health Organization (WHO) carried out global surveys on polychlorinated dibenzo- $p$-dioxins (PCDDs), polychlorinated dibenzofurans (PCDFs) and polychlorinated biphenyls (PCBs) in human milk. This study presents a review of the three most recent surveys from 2000 to 2010, including DDT. The objective was to identify global quantitative differences and provide baseline information for 52 countries or provide time-trends for countries with previous data. Individual human milk samples were collected following a WHO-designed procedure and combined to form a national pooled sample. Here, we report global levels for PCDDs, PCDFs, PCBs and the sum of $o, p^{\prime}$-DDT, $p, p^{\prime}$-DDT, $o, p^{\prime}-$ DDE, $p, p^{\prime}$-DDE, $o, p^{\prime}$-DDD and $p, p^{\prime}$-DDD ( $\Sigma$ DDTs). A concise risk-benefit evaluation related to human milk contamination with these persistent organic pollutants (POPs) was also done. Large global and regional differences were
\end{abstract}

Martin van den Berg

m.vandenberg@uu.nl

1 Institute for Risk Assessment Sciences (IRAS), Utrecht University, P.O. Box 80177, 3508 TD Utrecht, The Netherlands

2 WHO/UNEP Reference Laboratory, State Institute for Chemical and Veterinary Analysis of Food (CVUA), Bissierstrasse 5, 79114 Freiburg, Germany

3 Department of Food Safety and Zoonoses, World Health Organization, Ave Appia 20, 1211 Geneva 27, Switzerland

4 Stockholm Convention Secretariat, United Nations Environment Programme (UNEP), International Environment House, 1219 Châtelaine, Geneva, Switzerland

5 Division of Technology, Industry and Economics/Chemical Branch, United Nations Environment Programme (UNEP), Chemin des Anémones 11-13, 1219 Châtelaine, Geneva, Switzerland observed. Levels of PCDDs and PCDFs were highest in India and some European and African countries. PCB levels were highest in East and West Europe. The highest levels of $\boldsymbol{\Sigma}$ DDTs were found in less industrialized countries. A temporal downward trend for PCDDs, PCDFs and PCBs is indicated. A risk-benefit assessment indicates that human milk levels of PCDDs, PCDFs and PCBs are still significantly above those considered toxicologically safe, while $\boldsymbol{\Sigma}$ DDTs are below or around those considered safe. With respect to potential adverse health effects, a more dominant role of in utero exposure versus lactational exposure is indicated. If potential adverse effects are balanced against positive health aspects for (breastfed) infants, the advantages of breastfeeding far outweigh the possible disadvantages. Our observations provide a strong argument to plea for further global source-directed measures to reduce human exposure further to dioxin-like compounds.

Keywords Human milk $\cdot$ Dioxins $\cdot$ PCBs $\cdot$ DDT Breastfeeding $\cdot$ Benefit-risk

\section{Introduction}

Since the mid-eighties, the World Health Organization (WHO) coordinates a comprehensive global monitoring program on polychlorinated biphenyls (PCBs), polychlorinated dibenzo- $p$-dioxins (PCDDs) and polychlorinated dibenzofurans (PCDFs) (Malisch et al. 2010; Malisch and Van Leeuwen 2003; WHO 1989, 1996). This program focuses particularly on the exposure of breastfed and aims to identify the impact of measures taken to reduce or prevent environmental exposure to these chemicals.

The Stockholm Convention on Persistent Organic Pollutants (POPs) has the objective to protect human health 
and environment from POPs by reducing or eliminating their releases into the environment. Under this convention, human milk was recommended as a core matrix for biomonitoring. To evaluate the effectiveness of the Stockholm Convention, the results from these human milk surveys will be used as a baseline to identify possible global temporal trends and spatial distributions of POPs. These surveys also provide a suitable basis for possible source-directed reduction measures of POPs in human food and milk on a country-by-country basis.

For biomonitoring of POPs, human milk is the best matrix to use, because it is easily available, collecting is non invasive, and its high lipid content makes the extraction of POPs easy (Liem et al. 2000). PCDDs, PCDFs and PCBs in human milk are also a good reflection of the body burden, as human blood and adipose tissue concentrations are often (closely) similar (Needham et al. 2011; Todaka et al. 2010).

Experimental and epidemiological studies indicate that the early life stage is most sensitive for the effects of dioxin-like (DL) compounds and PCBs (Birnbaum and Tuomisto 2000; Peterson et al. 1993). Therefore, placental transfer and uptake via human milk can be of toxicological significance. Consequently, the exposure of breastfed infants is a challenge for the benefit-risk assessment of human milk, because significant health benefits concur with possible adverse health effects of these POPs (Aliyu et al. 2010; Landrigan et al. 2002; Mead 2008).

This article reviews three global surveys of PCDDs, PCDFs, PCBs and DDT in human milk. These surveys are meant to identify worldwide differences of human milk contamination, but not meant to derive a "ranking" of countries with respect to risk assessment for the breastfed infant. Based on the global levels observed during these surveys, a concise benefit-risk evaluation is included for the breastfed infant.

\section{Analytical aspects}

The State Institute for Chemical and Veterinary Analysis of Food (Freiburg, Germany) analyzed the composite human milk samples from various countries following the earlier WHO-designed procedure (http://www.who.int/foodsafety/ chem/POPprotocol.pdf) (WHO 2007).

\section{Protocols}

In short, samples were collected following a protocol dealing primarily with number and type of samples, donor selection, storage, pooling and shipping of samples. Inclusion criteria for donating mothers were: (a) primiparae, (b) healthy, (c) exclusive breastfeeding to one child and (d) local resident for about 5 years. Furthermore, WHO requirements in conducting studies with human milk are: (a) breastfeeding should always be promoted and supported, (b) sampling should neither be an unnecessary burden to the mother nor compromise the nutritional status of the infant, (c) samples should be as representative of the relevant population of the country as possible, (d) donor selection should take into account possible contributing factors, e.g., dietary habits and demographic differences. Approval from all national ethics committee was obtained.

The third survey (2000-2003) included pooled milk samples from at least two well-defined groups of ten mothers. If possible, a high- and low-exposure group was selected. If more than one pooled sample was donated, the median value was used for comparison.

For the fourth (2005-2007) and fifth (2008-2010) surveys, pooled milk samples from at least 50 donors per country were used. The donors were considered representative for a general background situation in a specific country. The samples of individual mothers remain available for future analysis of other POPs.

In the third survey, 102 samples were analyzed for PCDDs, PCDFs, PCBs and partly for DDT. In the fourth and fifth survey 13 and 23 countries sent in, respectively, 16 and 28 samples. As the fourth and fifth surveys were done within a relatively short time period, it was decided to combine the data in this study. In Figs. 1 and 2, the participating countries for dioxin-like compounds and $\mathbf{\Sigma}$ DDTs are presented, while in Figs. 3, 4, 5 and 6, more detailed analytical data are presented for each country.

\section{Chemical analysis}

The analytical procedure for PCDDs, PCDFs and DLPCBs has been described earlier (Malisch et al. 2000; Malisch and Dilara 2007; Malisch and Van Leeuwen 2002). The limit of quantification (LOQ) expressed as WHO toxic equivalencies (TEQs) was $\sim 0.1 \mathrm{pg} / \mathrm{g}$ lipid. Toxic equivalency factors (TEFs) for DL compounds as proposed by the 2005 WHO expert meeting have been used (Van den Berg et al. 2006). The LOQ for individual non DLPCBs was $<0.05 \mathrm{ng} / \mathrm{g}$ lipid and for DDT, DDD and DDE $\sim 0.5 \mathrm{ng} / \mathrm{g}$ lipid. Concentrations of the indicator PCBs 28 , $52,101,138,153$ and 180 are expressed as the sum of these PCBs ( $\Sigma$ PCBs). The mono-ortho substituted PCB 118 has DL properties and included in the TEQ calculations.

The chemical analysis of DDT and its metabolites has been described earlier (Hedley et al. 2010; UNEP 2007). $\boldsymbol{\Sigma}$ DDTs concentrations were calculated after correction for molecular weight to provide the sum of $o, p^{\prime}$-DDT, $p, p^{\prime}$ DDT, $o, p^{\prime}$-DDE, $p, p^{\prime}$-DDE, $o, p^{\prime}$-DDD and $p, p^{\prime}$-DDD. 
Toxic equivalents (TEQ) levels for dioxin-like compounds analysed in the period 2000-2010 for specific countries

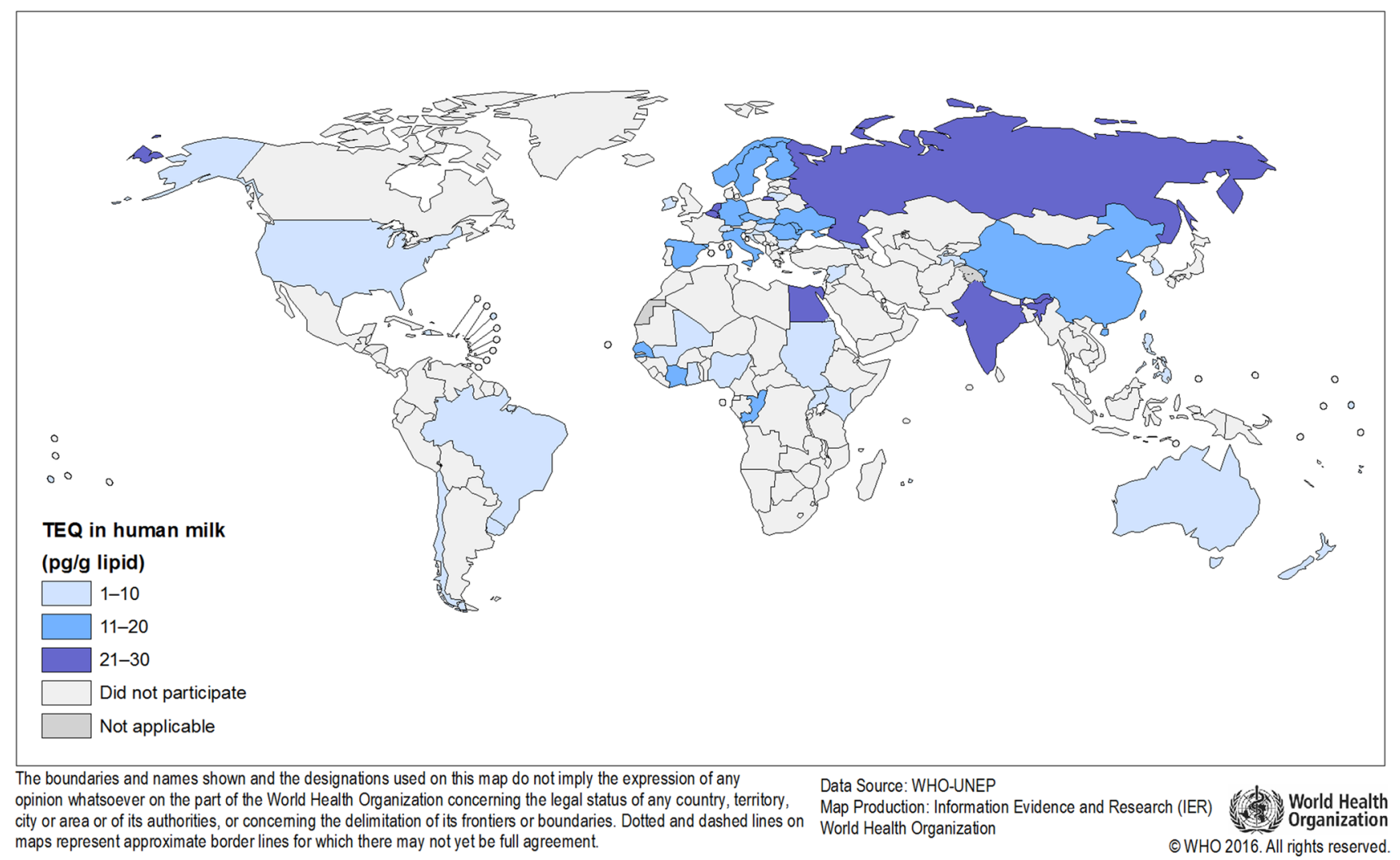

Fig. 1 Participating countries in the WHO/UNEP human milk global surveys and levels of dioxin-like compounds expressed in TEQs (Van den Berg et al. 2006)

\section{Global occurrence}

\section{PCDDs, PCDFs and PCBs}

\section{Third survey}

The results for the third survey (2000-2003) are shown in Figs. 3, 4, 5 and 6. Between countries, approximately one order of magnitude variation was found. The lowest concentrations of dioxin-like compounds were predominantly found in less industrialized countries (Fig. 1). Comparatively higher levels were found in the more highly industrialized European countries. Many Western and Eastern European countries had comparatively high levels of DLPCBs, with the highest observed in the Ukraine. Remarkably high levels of PCDDs and PCDFs were found in Egypt. In contrast, the levels of PCBs in Egypt were much lower compared to many other industrialized countries studied (Figs. 3, 4, 5). An almost linear relationship was found between PCDDs and PCDFs versus DL-PCBs that becomes less distinct at higher concentrations (Fig. 7a). For most industrialized countries, the contribution of PCDDs/PCDFs and DL-PCBs was approximately equal. The levels of indicator PCBs measured in the third survey vary widely between countries. In Europe, high levels were found in, e.g., the Czech Republic and Slovakia. Significantly lower levels were observed in the Southern Hemisphere (Fig. 5). As could be expected, a strong relationship between DL-PCBs and indicator $\Sigma$ PCBs was found (Fig. 7b).

\section{Fourth and fifth surveys}

The results of the combined fourth and fifth surveys (2005-2010) expressed in TEQ or $\Sigma$ PCBs are also shown in Figs. 3, 4, 5 and 6. Many countries provided only one pooled sample, and no median levels could be established. PCDD, PCDF and PCB levels were again by far the highest in Europe. The levels in less industrialized countries were significantly lower than those 


\section{DDT/E levels analysed in the period 2000-2010 for specific countries}

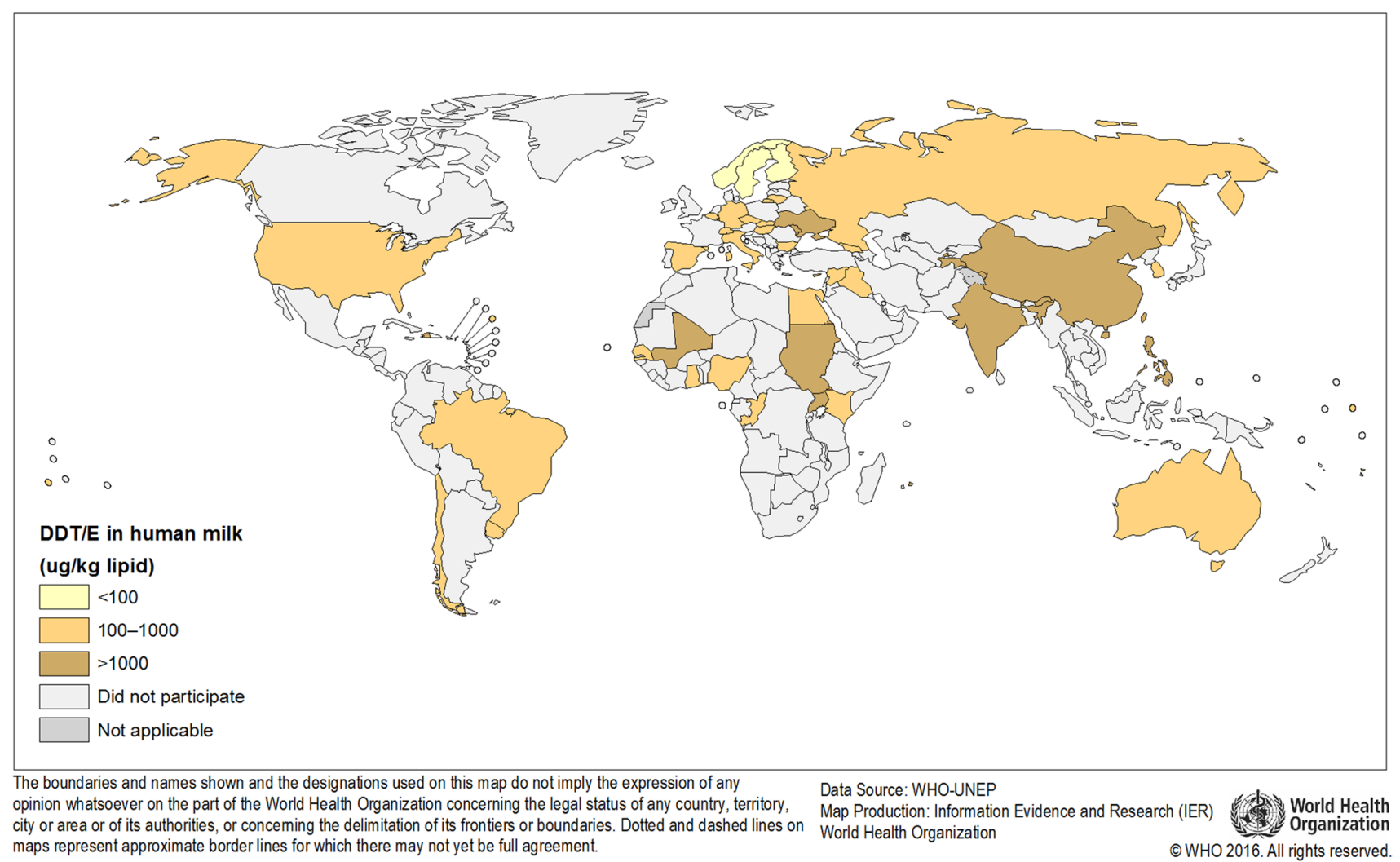

Fig. 2 Participating countries in the WHO/UNEP human milk global surveys and levels of $\mathbf{\Sigma}$ DDTs

in Europe. This survey period confirms again that many countries in the Southern Hemisphere have low levels of PCDDs, PCDFs and PCBs (Figs. 3, 4, 5). In Africa, the widest variation in contamination was observed. Kenya and Uganda had the lowest levels of PCDDs and PCDFs, while Côte d'Ivoire and the Democratic Republic of the Congo had the highest levels in these surveys (Fig. 3). It is noticeable that the latter countries did not have exceptional high levels of PCBs (Figs. 4, 5), indicating that the high PCDDs and PCDFs contamination is not associated with PCB-related occurrence. Most Asian countries studied in these surveys had relatively low levels of PCDDs/ PCDFs and PCBs. However, exceptional high levels of PCDDs and PCDFs were detected in India (Fig. 2), but levels of PCBs in this country were not high (Figs. 4, 5). Limited information was obtained from the Caribbean and Central/South American countries, but relatively low levels of PCDDs, PCDFs and PCBs were found for those countries studied. Similar, levels in Australia were low, indicating limited contamination of human milk with these compounds (see Fig. 1).
To detect a possible downward temporal trend of PCDDs, PCDFs and PCBs, a country-by-country comparison was made for those countries that participated in both survey periods (Fig. 8a-c). Although the number of countries that could be compared is limited, these results may indicate that PCDD, PCDF and PCB levels in human milk further declined in the first decade of the twenty-first century.

\section{DDT and metabolites}

The highest $\Sigma$ DDTs levels were found in a number of Asian countries and Haiti (Figs. 2, 6). The high EDDTs levels in Hong Kong SAR in the third survey are noticeable, but a significant reduction was observed in the fifth survey. Surprisingly, $\Sigma$ DDTs levels in Tajikistan were nearly a factor of three higher than in India. If the ranking order of $\Sigma$ DDTs levels is reviewed, the tropical countries represent the majority of the upper half of $\Sigma$ DDTs human milk levels. This observation certainly reflects its use in 
Fig. 3 Results of the WHO/ UNEP surveys for PCDDs and PCDFs in TEQs (pg/g lipid) in pooled human milk samples from different countries. The dotted red line represents the calculated safe level of these compounds for the breastfed infant (color figure online)

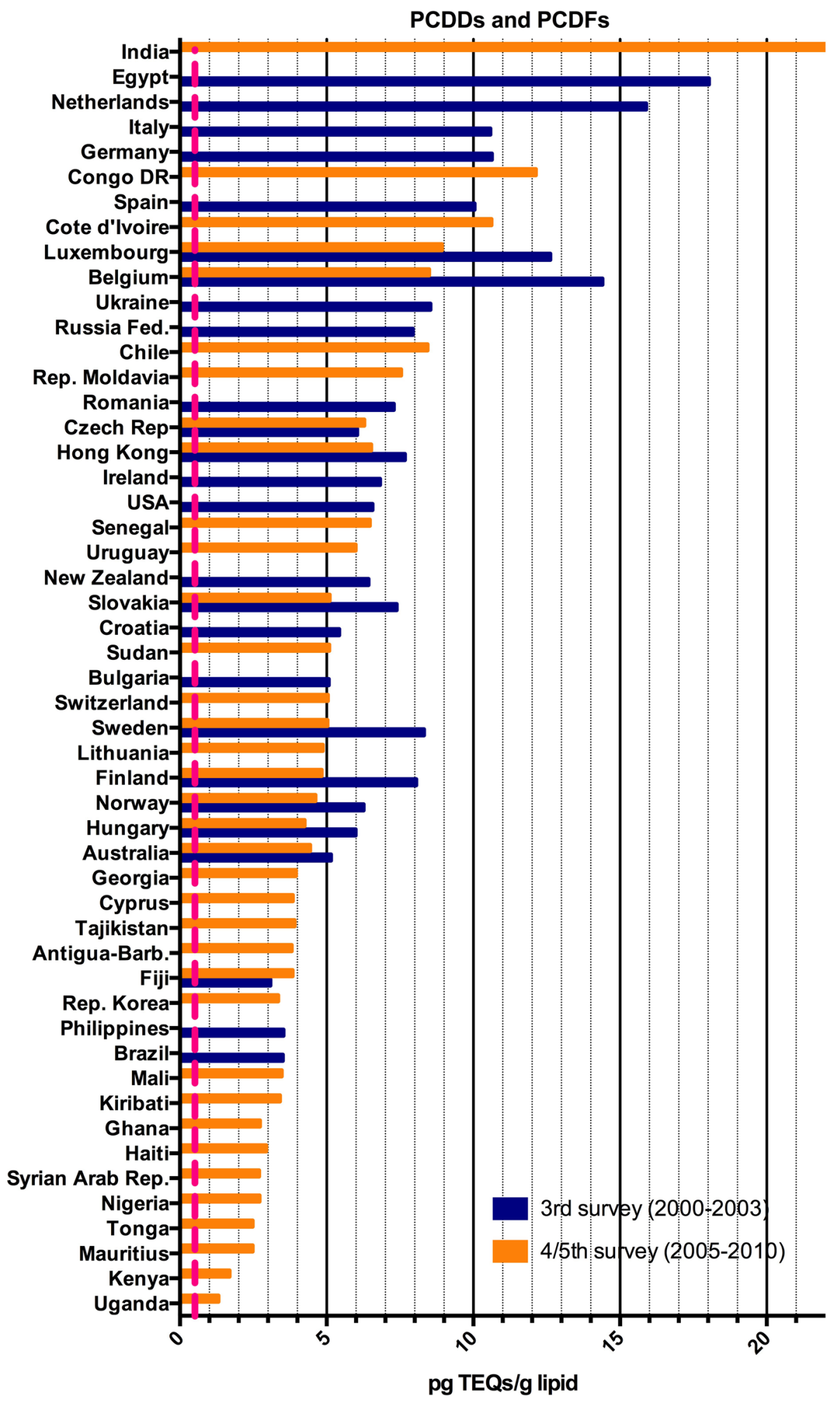

relation to the occurrence and prevention of malaria in these regions in recent times. In addition, it should be noted that no relationship was found between PCDDs, PCDFs and PCBs versus EDDTs levels, which illustrates the country-by-country differences in industrialization versus (former) malaria prevention with DDT (Fig. 7c, d). 
Fig. 4 Results of the WHO/ UNEP surveys for DL-PCBs in TEQs (pg/g lipid) in pooled human milk samples from different countries. The dotted red safe level of these compounds for the breastfed infant (color figure online) line represents the calculated

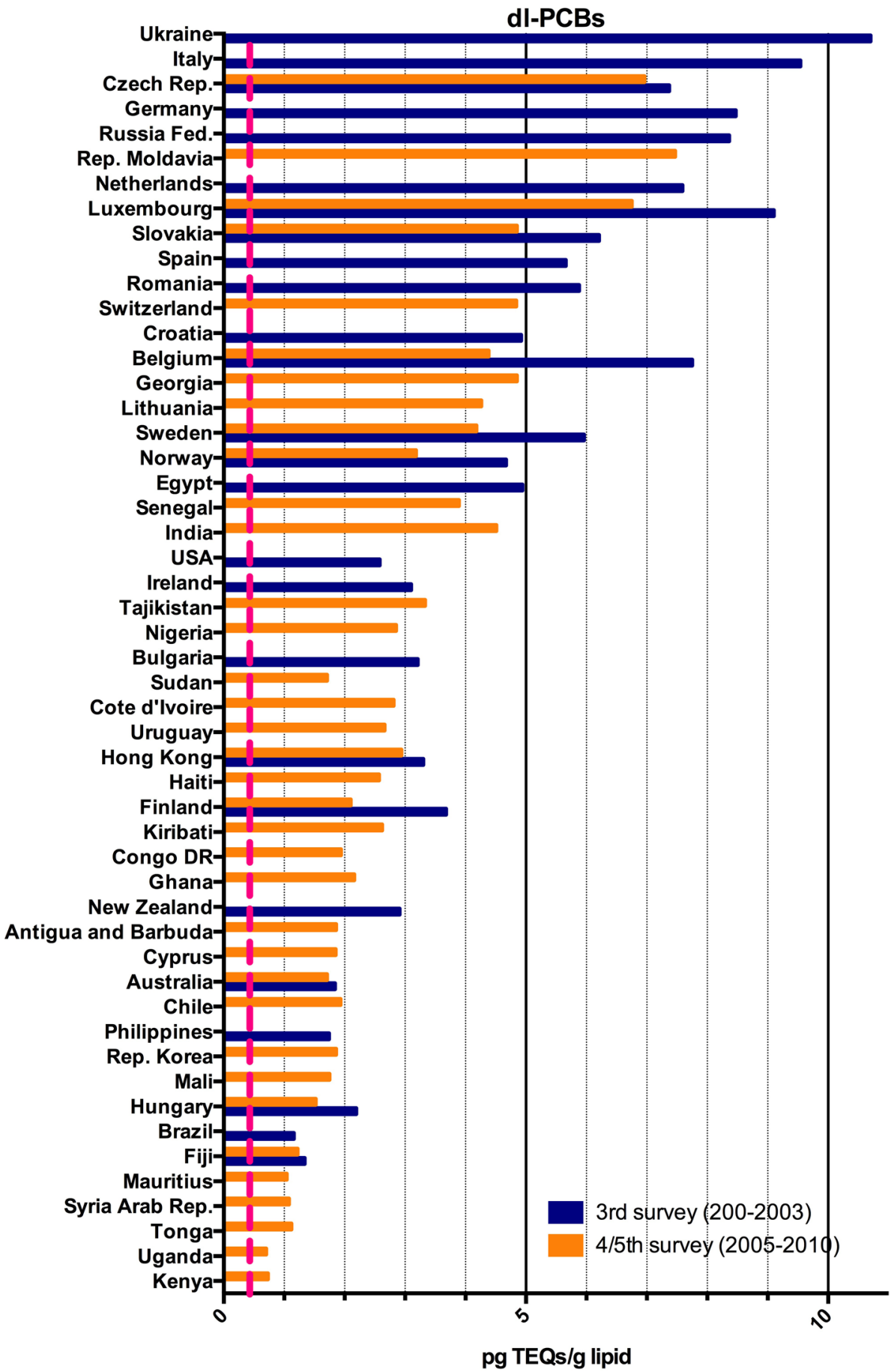

\section{Discussion}

\section{Global levels}

This study is the first in its kind reviewing global temporal and spatial contamination of PCDDs, PCDFs, PCBs and DDT of human milk. For many developing countries, this is the first time that such data are evaluated in a global perspective. Our results show that geographical areas with the highest levels are mostly associated with industrialization (Figs. 1, 2). In this review, the results of the fourth and fifth survey were combined. With approximately 5 years in between, we expected no major effect on the overall conclusions, because of the high environmental persistence and slowly decreasing levels of these POPs. Many European countries were found in the upper half ( $>5 \mathrm{pg}$ TEQs/g lipid) of the human milk levels of PCDDs and PCDFs (Fig. 3). Surprisingly, some less industrialized countries from Asia, 
Fig. 5 Results of the WHO/ UNEP surveys for the sum of the indicator PCBs in ng/g lipid in pooled human milk samples from different countries. The dotted red line represents the calculated safe level of these compounds for the breastfed infant (color figure online)

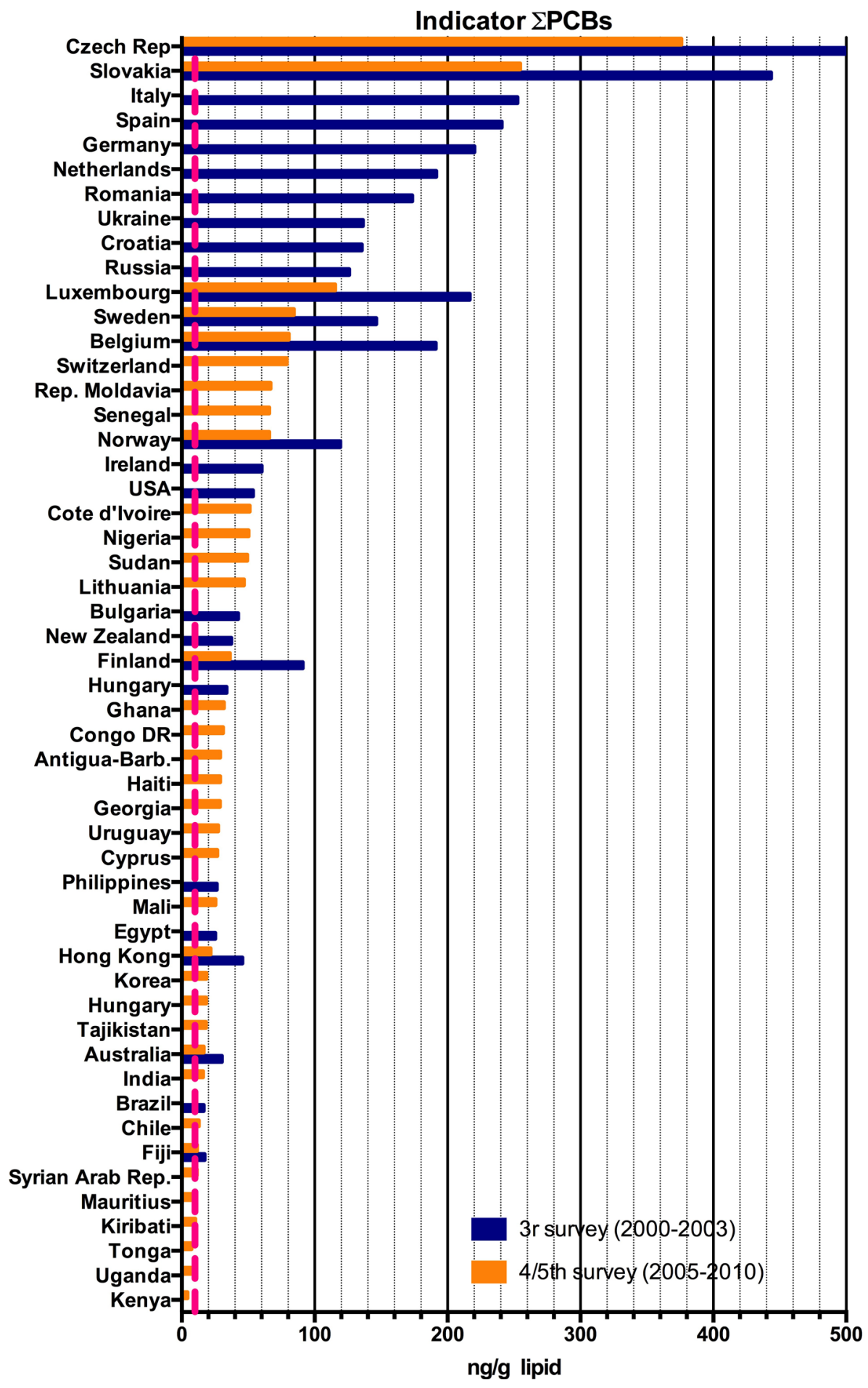

Africa and South America had similar high levels. In contrast, PCB levels in these non-European countries were relatively low, $<100 \mathrm{ng} / \mathrm{g}$ lipid (Figs. 4, 5). Thus, PCB contamination contributes little to the high levels of TEQs in these countries. Combustion and industrial processes more likely contribute to the human exposure of PCDDs and PCDFs (UNEP 2011). Clay consumption (geophagia) by pregnant women is the likely source of PCDD and PCDF exposure in some African countries that can lead to high levels in human milk (Reeuwijk et al. 2013). A downward trend appears to be present for DL compounds and PCBs during our two survey periods (Fig. $8 \mathrm{a}-\mathrm{c}$ ). A reduction in environmental levels during our surveys can be one explanation. However, the lower number of European countries 
Fig. 6 Results of the WHO/ UNEP surveys for the sum of DDT-like compounds in $\mu \mathrm{g} / \mathrm{kg}$ lipid in pooled human milk samples from different countries. The dotted red line represents the calculated safe level of these compounds for the breastfed infant (color figure online)

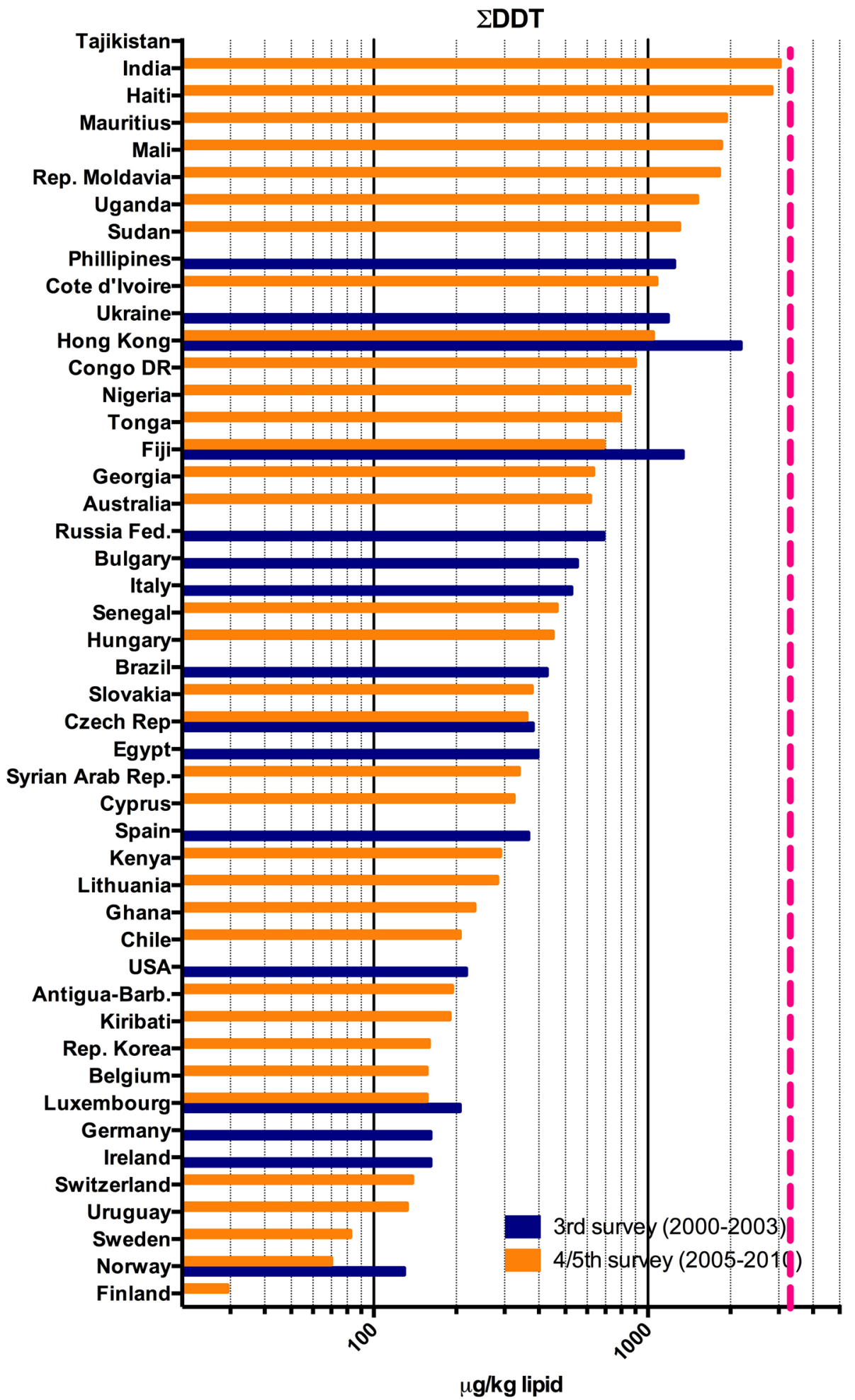

in the fourth and fifth surveys may also be responsible or contribute to this apparent decrease. To resolve this issue, time-trends should best be followed on country-by-country basis. This has already been done for, e.g., Germany, Norway, The Netherlands, Japan and the USA, and confirms a downward trend (Furst et al. 1994; LaKind et al. 2001;
Liem et al. 2000; Papke 1998). This suggests that the possible downward trend in the WHO surveys may indeed be real and no coincidence due to the pooled samples. The global distribution for EDDTs is almost exclusively associated with countries where malaria is still a significant health problem (Fig. 2). 
Relationship PCDD/Fs vs dl-PCBs

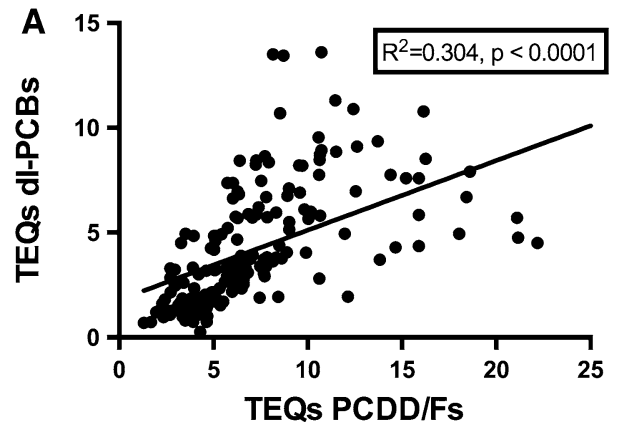

Relationship DDT vs Sum PCBs

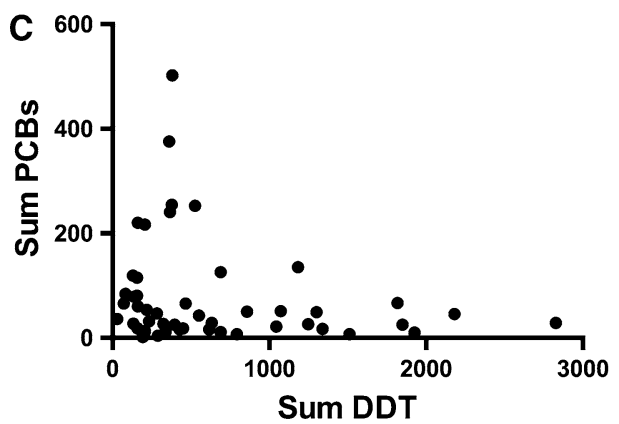

Relationship Sum PCBs vs dl-PCBs

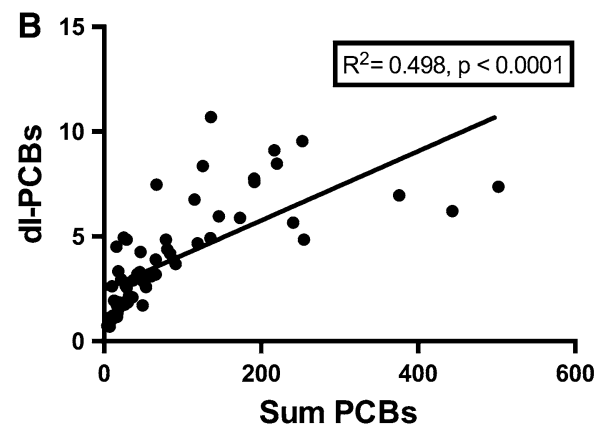

Relationship DDT vs PCDD/Fs

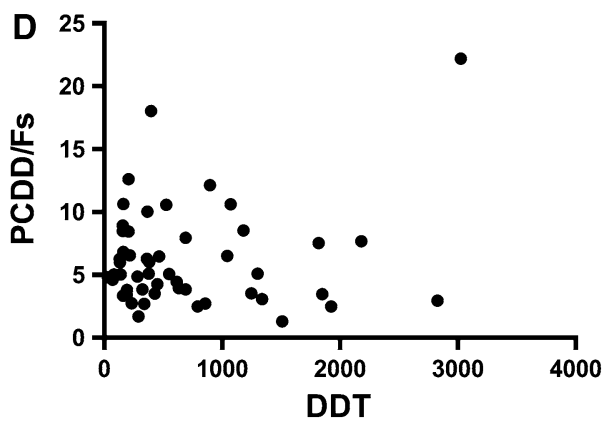

Fig. 7 Relationships between PCDD, PCDF, PCB and DDT levels in pooled human milk samples from the WHO/UNEP surveys

\section{Risks}

There is an ongoing discussion regarding the benefits versus risks of breastfeeding in relation to the presence of POPs in human milk. The WHO has always promoted exclusive breastfeeding because of its positive health aspects for the neonate and mother, but pros and con's remain. The results of this WHO/UNEP study can also be used to weight the benefits versus risks on a global level.

The WHO derived a Tolerable Daily and (Provisional) Monthly Intake (TDI or PTMI) for DL equivalents (TEQ) of 1-4 and $70 \mathrm{pg}$ TEQ $/ \mathrm{kg}$ bw per day or month, respectively (WHO 2000, 2002). The US-EPA proposed an oral reference dose (RfD) of $0.7 \mathrm{pg} \mathrm{TCDD} / \mathrm{kg}$ bw per day (USEPA 2010), and the ATSDR set a minimal risk level (MRL) for acute and semi-chronic exposure of 20 and $1 \mathrm{pg}$ TCDD/ $\mathrm{kg}$ bw per day, respectively (ATSDR 1998). By default, these safety standards are meant for chronic life time exposure and not applicable for the breastfeeding situation, which covers a much shorter time period of life. However, in-depth analysis of the underlying data shows that the most sensitive endpoints used to derive these safety standards often involve pre- or postnatal experimental studies. These effects include immune suppression, sperm count, genital malformation in rodents, while neurobehavioral effects are among the most sensitive endpoints in non-human primates (WHO 2000, 2002). Thus, scientifically sound arguments can be given to apply these TDI or PTMI values also for breastfed infant (Table 1).

Recently, the uptake via breastfeeding was estimated from 30 to more than $200 \mathrm{pg}$ TEQ $/ \mathrm{kg}$ bw per day ( $\mathrm{Li}$ et al. 2009) and our results are in line with these data. Therefore, it can be concluded that the WHO safety standards for DL compounds are exceeded with one to two orders of magnitude during a period from several months to more than a year for the breastfed infant from all countries studied in these surveys (Figs. 3, 4). For PCBs as a group, the ATSDR minimum risk level (MRL) is $0.03 \mu \mathrm{g} / \mathrm{kg}$ bw per day (ATSDR 2000), and again our review indicates that this safety standard is exceeded by one to two orders of magnitude for the countries included in these surveys (Fig. 5). Thus, in all countries studied, the levels in TEQs of DL compounds and $\Sigma$ PCBs in human milk and its associated maternal body burden are still one to two orders of magnitude above those considered toxicologically safe in early childhood.

Safety standards values have also been derived for DDT, and a provisional TDI of $10 \mu \mathrm{g} / \mathrm{kg}$ per day by the WHO was based on developmental toxicity in the rat (WHO 2001). The US-EPA and ATSDR both derived a RfD and MRL of $0.5 \mu \mathrm{g} / \mathrm{kg}$ bw per day for acute and intermediate oral exposure situations (ATSDR 2004; US-EPA 2011). The levels of $\Sigma$ DDTs are below or around those considered to be safe in the countries studied during these surveys 
TEQs PCDDs + PCDFs (pg/g lipid)

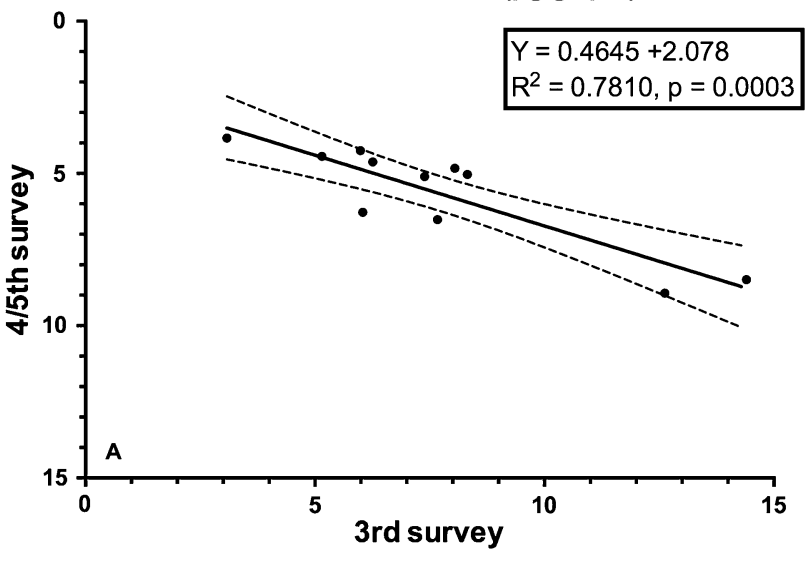

TEQs dl-PCBs (pg/g lipid)

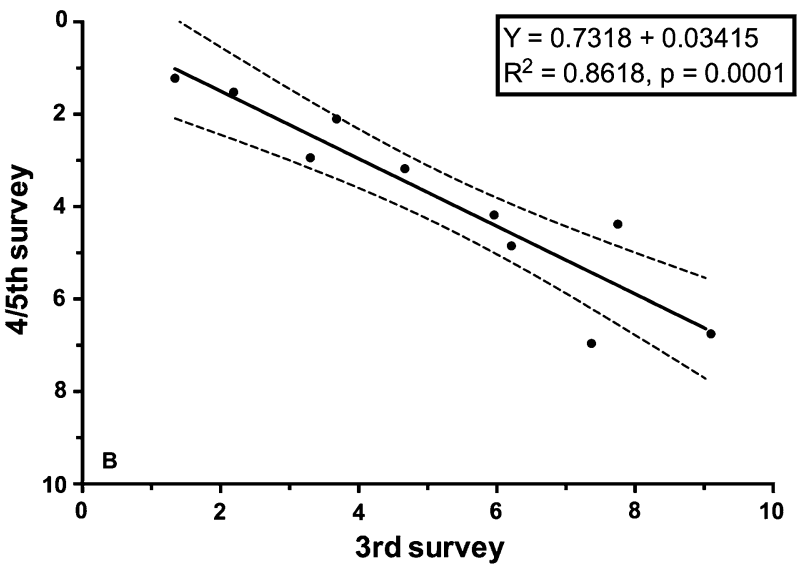

$\Sigma$ PCBs $\mathbf{n g} / \mathbf{g}$ lipid

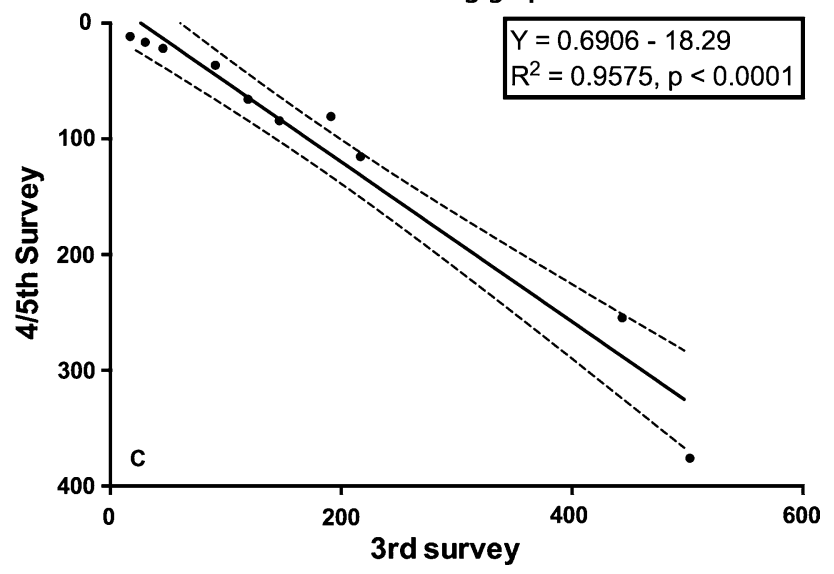

Fig. 8 Decline rates of PCDD, PCDF and PCB in some selected countries that have been studied during subsequent WHO/UNEP human milk survey periods (2000-2003 and 2005-2010)

(Fig. 6) and from a toxicological point may be considered as acceptable in human milk.

Several epidemiological studies have focused on the risks of pre- and postnatal exposure to DL compounds, and effects on thyroid hormones, immunology, psychomotor and physical development have been observed in the breastfed infant. However, these effects were often transient and their clinical relevance discussed (Koopman-Esseboom et al. 1994, 1996; Pluim et al. 1993; Weisglas-Kuperus et al. 1995, 2000, 2004). Very recently, a study from Spain and Greece reported a negative relationship between maternal levels of DL compounds and anogenital distance in newborns (Vafeiadi et al. 2013). Many of these studies could not differentiate between possible effects of DL compounds (in TEQ) or PCBs due to their simultaneous occurrence in human milk. However, several studies provide evidence that prenatal exposure is more important than breastfeeding, which is in line with results from experimental studies with rodents and monkeys (Peterson et al. 1993). Taken together, it must be concluded that over the last two decades maternal body burdens of DL compounds and/or PCBs in industrialized countries, reflected in human milk levels, were still sufficiently high to cause subtle effects in the neonatal and early childhood period.

Human health effects of DDT and its metabolites have also been extensively studied, and adverse health effects in the neonatal period or early childhood have been implicated (Eskenazi et al. 2009; WHO 2011). Again differentiation between effects due to in utero versus neonatal exposure is often not possible. Effects on thyroid hormones or growth in childhood or puberty have been reported, but results are not equivocal (Alvarez-Pedrerol et al. 2008; Asawasinsopon et al. 2006; Chevrier et al. 2008; Gladen et al. 2004; Karmaus et al. 2002; Rogan et al. 1987; Takser et al. 2005). These effects of DDT on thyroid hormones and body growth may well be transient, small and possibly not clinically relevant (Feeley and Brouwer 2000; Rogan et al. 1987).

More significant effects of DDT and/or DDE have been observed on neurocognitive and behavioral development that may persist into childhood (Darvill et al. 2000; Eskenazi et al. 2006; Gladen and Rogan 1991; Gladen et al. 1988; Pan et al. 2010; Ribas-Fito et al. 2006; Rogan et al. 1986; Torres-Sanchez et al. 2007). These effects are not consistent, but most indicate that the maternal body burden and placental transfer are more important than breastfeeding itself (Aliyu et al. 2010; Mead 2008). In addition, conflicting results have been obtained with respect to the transient nature of these cognitive developmental effects, but a prolonged effect into childhood cannot be excluded. In relation to this reduced cognitive or neurobehavioral development in breastfed infants, it must be recognized that experimental studies provide supporting evidence for such an effect (Arendt 2008).

Possible effects of DDT and/or DDE on the immune system have also been reported, but results are still inconclusive (Dallaire et al. 2004; Dewailly et al. 2000; Park et al. 2008; Sunyer et al. 2005). One study found a positive 
Table 1 Different safety standards for dioxin-like compounds (TEQ) and DDT with calculated equivalent human milk levels

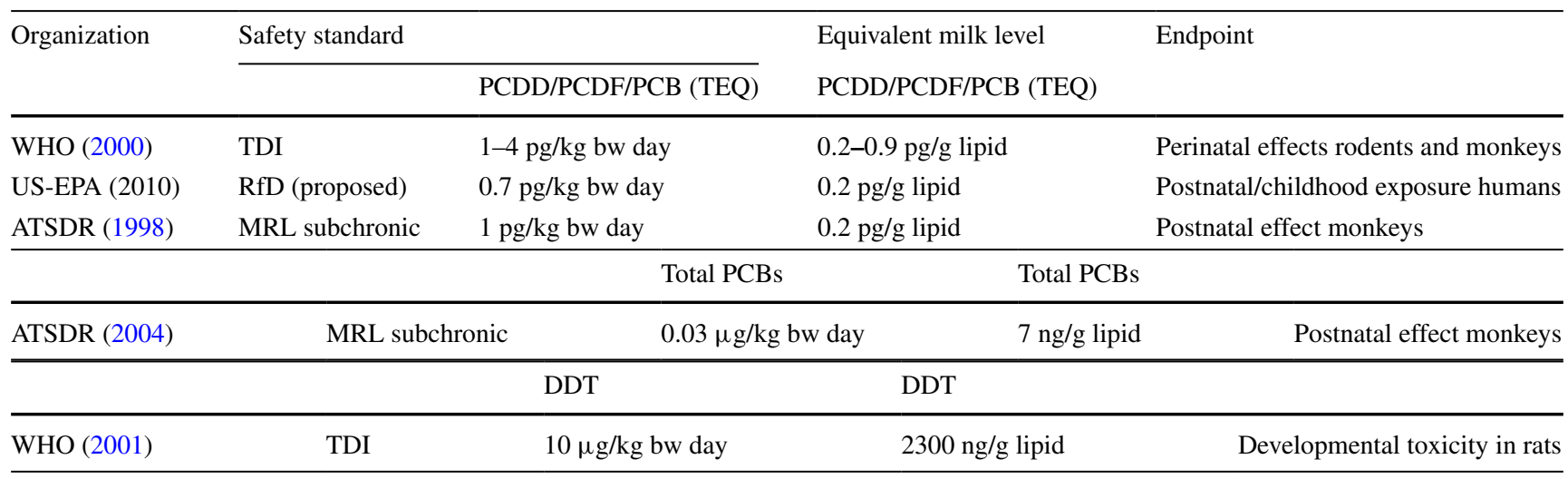

Information and formula used

Lipid set in human milk $=3.5 \%$ and consumption $125 \mathrm{~g}$ milk $/ \mathrm{kg}$ bw day [Acceptable concentration] $=\frac{[\text { Safety standard(pg or } \mu \mathrm{g} / \mathrm{kg} \text { bw day) }]}{4.375 \mathrm{~g} \mathrm{lipid} / \mathrm{kg} \text { bw day }}$

Table 2 General overview for the observed benefits of breastfeeding for the infant and mother (Ip et al. 2007; James et al. 2009)

\begin{tabular}{|c|c|}
\hline Benefits for the infant & Benefits for the mother \\
\hline Optimal nutrition & Strong bonding with infant \\
\hline Strong bonding with mother & Increased energy expenditure, faster return to prepregnancy weight \\
\hline Safe milk & Faster shrinking of the uterus \\
\hline Enhanced immune system & Reduced postpartum bleeding and delay menstrual cycle \\
\hline $\begin{array}{l}\text { Reduced risk of acute otitis media, gastroenteritis, lower respiratory } \\
\text { tract infections and asthma }\end{array}$ & $\begin{array}{l}\text { Decreased risk of chronic diseases, e.g., breast and ovarian cancer, } \\
\text { diabetes }\end{array}$ \\
\hline Protection against allergies and intolerances & Improved bone density, decreased risk hip fracture \\
\hline Correct development of jaw and teeth & Decreased risk postpartum depression \\
\hline Association with higher IQ/school performance & Enhanced self-esteem in the maternal role \\
\hline $\begin{array}{l}\text { Reduced risk of chronic diseases, e.g., obesity, diabetes, heart disease, } \\
\text { hypertension, hypercholesterolemia, childhood leukemia }\end{array}$ & $\begin{array}{l}\text { Time and money saved from preparing and not buying formula, less } \\
\text { medical expenses }\end{array}$ \\
\hline \multicolumn{2}{|l|}{ Reduced risk of sudden infant death syndrome } \\
\hline Reduced risk of overall morbidity and mortality & \\
\hline
\end{tabular}

relationship between prenatal DDE exposure and infection rate, but a confounding role of DL compounds could not be excluded (Dallaire et al. 2004).

Possible anti-androgenic effects after perinatal exposure to DDT and/or DDE in relation to hypospadias, anogenital distance and chryptochordism have also been studied (Bhatia et al. 2005; Brucker-Davis et al. 2008; Damgaard et al. 2006; Flores-Luevano et al. 2003; Longnecker et al. 2002, 2007). None of these studies provided conclusive evidence that pre- or postnatal exposure were associated with negative effects on the male development.

\section{Benefits}

Over the last decades, the benefits of breastfeeding for the infant and mother have been advocated extensively (Horta et al. 2007; James et al. 2009; WHO 2011). Thus, in any risk-benefit analysis the positive health effects of breastfeeding must be balanced against possible adverse health effects of these POPs. A large number of neonatal studies established significant positive health aspects of breastfeeding, but it is beyond the scope of our study to review all these studies in detail. In this review, we restrict ourselves to major outcomes and conclusions on this topic.

The most extensive and recent review on the positive health aspects of breastfeeding was done by the US Department of Health and Human Services, which included approximately 400 studies. It is concluded that breastfeeding reduces a large variety of health problems in early childhood, including the risk of acute otitis media, nonspecific gastroenteritis, severe lower respiratory tract infections, atopic dermatitis, asthma (young children), obesity, possibly type 1 and 2 diabetes, childhood leukemia, SIDS and necrotizing enterocolitis (Ip et al. 2007). Quantifiable benefits of breastfeeding with respect to overall postnatal survival and hospitalization have also been reported, with a $30-40 \%$ reduction in overall neonatal mortality and sudden infant death when breastfeeding. Furthermore, a longer 
breastfeeding period was associated with a decreasing risk in health problems (Chen and Rogan 2004). A study from Spain indicated that $30 \%$ of the neonatal hospital admissions could be avoided for every additional month of breastfeeding (Paricio Talayero et al. 2006). Thus, there is compelling evidence that breastfeeding is associated with a reduced mortality and morbidity with many beneficial health effects for later life stages. In contrast, adverse health effects of POPs in human milk appear mostly transient in nature and less significant from a clinical point of view. The possible exception may be a reduced cognitive performance that can persist in later life (Ribas-Fito et al. 2006). In Table 2, a general overview is given for the observed benefits of breastfeeding for the infant and mother (Ip et al. 2007; James et al. 2009).

\section{Conclusions and future perspectives}

Based on our present knowledge, we conclude that the benefits of breastfeeding far outweigh the toxicological disadvantages that are associated with certain POPs. Subtle adverse health effects of DL compounds for the fetus and infant can still be expected from prenatal exposure due to current maternal body burdens that can still be found in many countries around the globe. Experimental and epidemiological studies indicate that future risk-benefit assessments should focus more on the in utero situation, rather than on the breastfeeding period. Consequently, the risk-benefit debate of breastfeeding may well be redundant. The results of our global monitoring study indicate that recent human exposure to DL compounds and PCBs is still above those considered toxicologically safe for the fetus and breastfed infant, while those for DDT would be acceptable for the countries studied. Our observations provide a strong argument to plea for further global source-directed measures to reduce human exposure further to dioxin-like compounds.

Acknowledgments On behalf of WHO and UNEP, the authors express their gratitude to the national coordinators of the joint $\mathrm{WHO} /$ UNEP exposure study for all the work done to collect the human milk samples. We also thank Renate Tritschler and Helmut Winterhalter for performance of the dioxin and PCB analyses, Ina Wegert, Ralf Brandstetter and Manfred Grosse for performance of the pesticide analyses and Kerstin Wahl, Nicole Bitomsky, Biljana Trajkovska and Karin Malisch for their scientific support and cooperation with the national coordinators. Finally, our thanks go to Drs. FX Rolaf van Leeuwen, Gerald Moy and Seongsoo Park for their important scientific support and assistance during various stages of this study.

Open Access This article is distributed under the terms of the Creative Commons Attribution 4.0 International License (http://creativecommons.org/licenses/by/4.0/), which permits unrestricted use, distribution, and reproduction in any medium, provided you give appropriate credit to the original author(s) and the source, provide a link to the Creative Commons license, and indicate if changes were made.

\section{References}

Aliyu MH, Alio AP, Salihu HM (2010) To breastfeed or not to breastfeed: a review of the impact of lactational exposure to polychlorinated biphenyls (PCBs) on infants. J Environ Health 73(3):814; quiz 32

Alvarez-Pedrerol M, Ribas-Fito N, Torrent M et al (2008) Thyroid disruption at birth due to prenatal exposure to beta-hexachlorocyclohexane. Environ Int 34(6):737-740. doi:10.1016/j. envint.2007.12.001

Arendt M (2008) Communicating human biomonitoring results to ensure policy coherence with public health recommendations: analysing breastmilk whilst protecting, promoting and supporting breastfeeding. Environ Health 7(Suppl 1):S6. doi:10.1186/1476-069X-7-S1-S6

Asawasinsopon R, Prapamontol T, Prakobvitayakit O, Vaneesorn Y, Mangklabruks A, Hock B (2006) The association between organochlorine and thyroid hormone levels in cord serum: a study from northern Thailand. Environ Int 32(4):554-559. doi:10.1016/j.envint.2006.01.001

ATSDR (1998) Toxicological Profile for Chlorinated Dibenzo- $p$-dioxins. In: U.S. Department of Health and Human Services PHS (ed). Agency for Toxic Substances and Disease Registry, Atlanta, GA, USA

ATSDR (2000) Toxicological Profile for PCBs. In: U.S. Department of Health and Human Services PHS (ed). Agency for Toxic Substances and Disease Registry, Atlanta, GA, USA

ATSDR (2004) Toxicological profile for DDT, DDE and DDD. In: U.S. Department of Health and Human Services PHS (ed). Agency for Toxic Substances and Disease Registry, Atlanta, GA, USA

Bhatia R, Shiau R, Petreas M, Weintraub JM, Farhang L, Eskenazi B (2005) Organochlorine pesticides and male genital anomalies in the child health and development studies. Environ Health Perspect 113(2):220-224

Birnbaum LS, Tuomisto J (2000) Non-carcinogenic effects of TCDD in animals. Food Addit Contam 17(4):275-288. doi:10.1080/026520300283351

Brucker-Davis F, Wagner-Mahler K, Delattre I et al (2008) Cryptorchidism at birth in Nice area (France) is associated with higher prenatal exposure to PCBs and DDE, as assessed by colostrum concentrations. Hum Reprod 23(8):1708-1718. doi:10.1093/ humrep/den 186

Chen A, Rogan WJ (2004) Breastfeeding and the risk of postneonatal death in the United States. Pediatrics 113(5):e435-e439

Chevrier J, Eskenazi B, Holland N, Bradman A, Barr DB (2008) Effects of exposure to polychlorinated biphenyls and organochlorine pesticides on thyroid function during pregnancy. Am J Epidemiol 168(3):298-310. doi:10.1093/aje/kwn136

Dallaire F, Dewailly E, Muckle G et al (2004) Acute infections and environmental exposure to organochlorines in Inuit infants from Nunavik. Environ Health Perspect 112(14):1359-1365

Damgaard IN, Skakkebaek NE, Toppari J et al (2006) Persistent pesticides in human breast milk and cryptorchidism. Environ Health Perspect 114(7):1133-1138

Darvill T, Lonky E, Reihman J, Stewart P, Pagano J (2000) Prenatal exposure to PCBs and infant performance on the fagan test of infant intelligence. Neurotoxicology 21(6):1029-1038

Dewailly E, Ayotte P, Bruneau S, Gingras S, Belles-Isles M, Roy R (2000) Susceptibility to infections and immune status in Inuit infants exposed to organochlorines. Environ Health Perspect 108(3):205-211

Eskenazi B, Marks AR, Bradman A et al (2006) In utero exposure to dichlorodiphenyltrichloroethane (DDT) and dichlorodiphenyldichloroethylene (DDE) and neurodevelopment among 
young Mexican American children. Pediatrics 118(1):233-241. doi:10.1542/peds.2005-3117

Eskenazi B, Chevrier J, Rosas LG et al (2009) The Pine River statement: human health consequences of DDT use. Environ Health Perspect 117(9):1359-1367. doi:10.1289/ehp.11748

Feeley M, Brouwer A (2000) Health risks to infants from exposure to PCBs. PCDDs and PCDFs. Food Addit Contam 17(4):325-333. doi:10.1080/026520300283397

Flores-Luevano S, Farias P, Hernandez M et al (2003) DDT/DDE concentrations and risk of hypospadias. Pilot case-control study. Salud Publica Mex 45(6):431-438

Furst P, Furst C, Wilmers K (1994) Human milk as a bioindicator for body burden of PCDDs, PCDFs, organochlorine pesticides, and PCBs. Environ Health Perspect 102(Suppl 1):187-193

Gladen BC, Rogan WJ (1991) Effects of perinatal polychlorinated biphenyls and dichlorodiphenyl dichloroethene on later development. J Pediatr 119(1 Pt 1):58-63

Gladen BC, Rogan WJ, Hardy P, Thullen J, Tingelstad J, Tully M (1988) Development after exposure to polychlorinated biphenyls and dichlorodiphenyl dichloroethene transplacentally and through human milk. J Pediatr 113(6):991-995

Gladen BC, Klebanoff MA, Hediger ML et al (2004) Prenatal DDT exposure in relation to anthropometric and pubertal measures in adolescent males. Environ Health Perspect 112(17):1761-1767

Hedley AJ, Hui LL, Kypke K et al (2010) Residues of persistent organic pollutants (POPs) in human milk in Hong Kong. Chemosphere 79(3):259-265. doi:10.1016/j.chemosphere.2010.01.047

Horta BL, Bahl R, Martines JC, Victora CG (2007) Evidence on the long-term effects of breastfeeding-systematic reviews and meta-analyses. World Health Organization, Geneva

Ip S, Chung M, Raman G et al (2007) Breastfeeding and maternal and infant health outcomes in developed countries. Evid Rep Technol Assess (Full Rep)(153):1-186

James DC, Lessen R, American Dietetic A (2009) Position of the American Dietetic Association: promoting and supporting breastfeeding. J Am Diet Assoc 109(11):1926-1942

Karmaus W, Asakevich S, Indurkhya A, Witten J, Kruse H (2002) Childhood growth and exposure to dichlorodiphenyl dichloroethene and polychlorinated biphenyls. J Pediatr 140(1):33-39. doi: $10.1067 / \mathrm{mpd} .2002 .120764$

Koopman-Esseboom C, Morse DC, Weisglas-Kuperus N et al (1994) Effects of dioxins and polychlorinated biphenyls on thyroid hormone status of pregnant women and their infants. Pediatr Res 36(4):468-473. doi:10.1203/00006450-199410000-00009

Koopman-Esseboom C, Weisglas-Kuperus N, de Ridder MA, Van der Paauw CG, Tuinstra LG, Sauer PJ (1996) Effects of polychlorinated biphenyl/dioxin exposure and feeding type on infants' mental and psychomotor development. Pediatrics 97(5):700-706

LaKind JS, Berlin CM, Naiman DQ (2001) Infant exposure to chemicals in breast milk in the United States: what we need to learn from a breast milk monitoring program. Environ Health Perspect 109(1):75-88

Landrigan PJ, Sonawane B, Mattison D, McCally M, Garg A (2002) Chemical contaminants in breast milk and their impacts on children's health: an overview. Environ Health Perspect 110(6):A313-A315

Li J, Zhang L, Wu Y et al (2009) A national survey of polychlorinated dioxins, furans (PCDD/Fs) and dioxin-like polychlorinated biphenyls (dl-PCBs) in human milk in China. Chemosphere 75(9):1236-1242. doi:10.1016/j.chemosphere.2009.01.073

Liem AK, Furst P, Rappe C (2000) Exposure of populations to dioxins and related compounds. Food Addit Contam 17(4):241-259. doi:10.1080/026520300283324

Longnecker MP, Klebanoff MA, Brock JW et al (2002) Maternal serum level of 1,1-dichloro-2,2-bis( $p$-chlorophenyl)ethylene and risk of cryptorchidism, hypospadias, and polythelia among male offspring. Am J Epidemiol 155(4):313-322
Longnecker MP, Gladen BC, Cupul-Uicab LA et al (2007) In utero exposure to the antiandrogen 1,1-dichloro-2,2-bis(p-chlorophenyl)ethylene (DDE) in relation to anogenital distance in male newborns from Chiapas, Mexico. Am J Epidemiol 165(9):10151022. doi:10.1093/aje/kwk109

Malisch R, Dilara P (2007) PCDD/Fs and PCBs in butter samples from new European Union member states and a candidate country: analytical quality control, results and certain PCBspecific aspects. Chemosphere 67(9):S79-S89. doi:10.1016/j. chemosphere.2006.05.150

Malisch R, Van Leeuwen FXR (2002) Third round of WHO-coordinated exposure study: analysis of PCDDs, PCDFs and PCBs in human milk. Organohalogen Compd 56:317-320

Malisch R, Van Leeuwen FXR (2003) Results of the WHO-coordinated exposure study on the levels of PCBs, PCDDs and PCDFs in human milk. Organohalogen Compd 64:140-143

Malisch R, Bruns-Weller E, Knoll A, Furst P, Mayer R, Wiesmuller T (2000) Results of an "emergency quality control study" as confirmation of a PCDD/PCDF-contamination of milk and butter samples. Chemosphere 40(9-11):1033-1040

Malisch R, Kypke K, Wahl K, Bitomsky N, Moy G, Park S (2010) WHO/UNEP-coordinated exposure study (2008-2009) on levels of persistent organic pollutants (POPs) in human milk with regard to the global monitoring plan. Organohalogen Compd 72:4-8

Mead MN (2008) Contaminants in human milk: weighing the risks against the benefits of breastfeeding. Environ Health Perspect 116(10):A427-A434

Needham LL, Grandjean P, Heinzow B et al (2011) Partition of environmental chemicals between maternal and fetal blood and tissues. Environ Sci Technol 45(3):1121-1126. doi:10.1021/es1019614

Pan IJ, Daniels JL, Herring AH et al (2010) Lactational exposure to polychlorinated biphenyls, dichlorodiphenyltrichloroethane, and dichlorodiphenyldichloroethylene and infant growth: an analysis of the Pregnancy, Infection, and Nutrition Babies Study. Paediatr Perinat Epidemiol 24(3):262-271. doi:10.1111/j.1365-3016.2010.01114.x

Papke O (1998) PCDD/PCDF: human background data for Germany, a 10-year experience. Environ Health Perspect 106(Suppl 2):723-731

Paricio Talayero JM, Lizan-Garcia M, Otero Puime A et al (2006) Full breastfeeding and hospitalization as a result of infections in the first year of life. Pediatrics 118(1):e92-e99. doi:10.1542/ peds.2005-1629

Park HY, Hertz-Picciotto I, Petrik J, Palkovicova L, Kocan A, Trnovec $\mathrm{T}$ (2008) Prenatal PCB exposure and thymus size at birth in neonates in Eastern Slovakia. Environ Health Perspect 116(1):104109. doi: $10.1289 /$ ehp. 9769

Peterson RE, Theobald HM, Kimmel GL (1993) Developmental and reproductive toxicity of dioxins and related compounds: cross-species comparisons. Crit Rev Toxicol 23(3):283-335. doi:10.3109/10408449309105013

Pluim HJ, de Vijlder JJ, Olie K et al (1993) Effects of pre- and postnatal exposure to chlorinated dioxins and furans on human neonatal thyroid hormone concentrations. Environ Health Perspect 101(6):504-508

Reeuwijk NM, Talidda A, Malisch R et al (2013) Dioxins (polychlorinated dibenzo- $p$-dioxins and polychlorinated dibenzo-furans) in traditional clay products used during pregnancy. Chemosphere 90(5):1678-1685. doi:10.1016/j.chemosphere.2012.09.064

Ribas-Fito N, Torrent M, Carrizo D et al (2006) In utero exposure to background concentrations of DDT and cognitive functioning among preschoolers. Am J Epidemiol 164(10):955-962. doi:10.1093/aje/kwj299

Rogan WJ, Gladen BC, McKinney JD et al (1986) Neonatal effects of transplacental exposure to PCBs and DDE. J Pediatr 109(2):335-341 
Rogan WJ, Gladen BC, McKinney JD et al (1987) Polychlorinated biphenyls (PCBs) and dichlorodiphenyl dichloroethene (DDE) in human milk: effects on growth, morbidity, and duration of lactation. Am J Public Health 77(10):1294-1297

Sunyer J, Torrent M, Munoz-Ortiz L et al (2005) Prenatal dichlorodiphenyldichloroethylene (DDE) and asthma in children. Environ Health Perspect 113(12):1787-1790

Takser L, Mergler D, Baldwin M, de Grosbois S, Smargiassi A, Lafond J (2005) Thyroid hormones in pregnancy in relation to environmental exposure to organochlorine compounds and mercury. Environ Health Perspect 113(8):1039-1045

Todaka T, Hirakawa H, Kajiwara J et al (2010) Relationship between the concentrations of polychlorinated dibenzo-p-dioxins, polychlorinated dibenzofurans, and polychlorinated biphenyls in maternal blood and those in breast milk. Chemosphere 78(2):185-192. doi:10.1016/j.chemosphere.2009.09.047

Torres-Sanchez L, Rothenberg SJ, Schnaas L et al (2007) In utero $p, p^{\prime}$-DDE exposure and infant neurodevelopment: a perinatal cohort in Mexico. Environ Health Perspect 115(3):435-439. doi:10.1289/ehp.9566

UNEP (2007) Guidance on the Global Monitoring Plan for Persistent Organic Pollutants. In: Secretariat of the Stockholm Convention. http://www.pops.int/documents/meetings/cop_3/meetingdocs/ inf14/GMPGuidanceCD/Guidance.pdf

UNEP (2011) Climate change and POPS: predicting the impacts. Report of the UNEP/AMAP Expert Group Secretariat of the Stockholm Convention, Geneva, Switzerland

US-EPA (2010) EPA's reanalysis of key issues related to dioxin toxicity and response to NAS comments. United States Environmental Protection Agency. United States Environmental Protection Agency, Washington DC

US-EPA (2011) p, $\mathrm{p}^{\prime}$-Dichlorodiphenyltrichloroethane (DDT) (CASRN 50-29-3). United States Environmental Protection Agency

Vafeiadi M, Agramunt S, Papadopoulou E et al (2013) In utero exposure to dioxins and dioxin-like compounds and anogenital distance in newborns and infants. Environ Health Perspect 121(1):125-130. doi:10.1289/ehp.1205221
Van den Berg M, Birnbaum LS, Denison M et al (2006) The 2005 World Health Organization reevaluation of human and Mammalian toxic equivalency factors for dioxins and dioxin-like compounds. Toxicol Sci 93(2):223-241. doi:10.1093/toxsci/kfl055

Weisglas-Kuperus N, Sas TC, Koopman-Esseboom C et al (1995) Immunologic effects of background prenatal and postnatal exposure to dioxins and polychlorinated biphenyls in Dutch infants. Pediatr Res 38(3):404-410. doi:10.1203/00006450-199509000-00022

Weisglas-Kuperus N, Patandin S, Berbers GA et al (2000) Immunologic effects of background exposure to polychlorinated biphenyls and dioxins in Dutch preschool children. Environ Health Perspect 108(12):1203-1207

Weisglas-Kuperus N, Vreugdenhil HJ, Mulder PG (2004) Immunological effects of environmental exposure to polychlorinated biphenyls and dioxins in Dutch school children. Toxicol Lett 149(1-3):281-285. doi:10.1016/j.toxlet.2003.12.039

WHO (1989) Levels of PCBs, PCDDs, and PCDFs in breast milk. World Health Organization, Copenhagen

WHO (1996) Levels of PCBs, PCDDs and PCDFs in human milk: Second round of WHO-coordinated exposure study. World Health Organization, Copenhagen

WHO (2000) Assessment of the health risk of dioxins: re-evaluation of the tolerable daily intake (TDI). Geneva, Switzerland, 25-29 May 1998. Food Addit Contam 17(4):223-369

WHO (2001) DDT (Addendum). World Health Organization, Geneva

WHO (2002) Evaluation of certain food additives and contaminants. World Health Organization, Geneva

WHO (2007) WHO protocol Fourth WHO-Coordinated Survey of Human Milk for Persistent Organic Pollutants in Cooperation with UNEP Guidelines for Developing a National Protocol, Revised. In: World Health Organization. http://www.who.int/ foodsafety/chem/POPprotocol.pdf

WHO (2011) DDT in indoor residual spraying: Human health aspects. World Health Organization, Geneva 